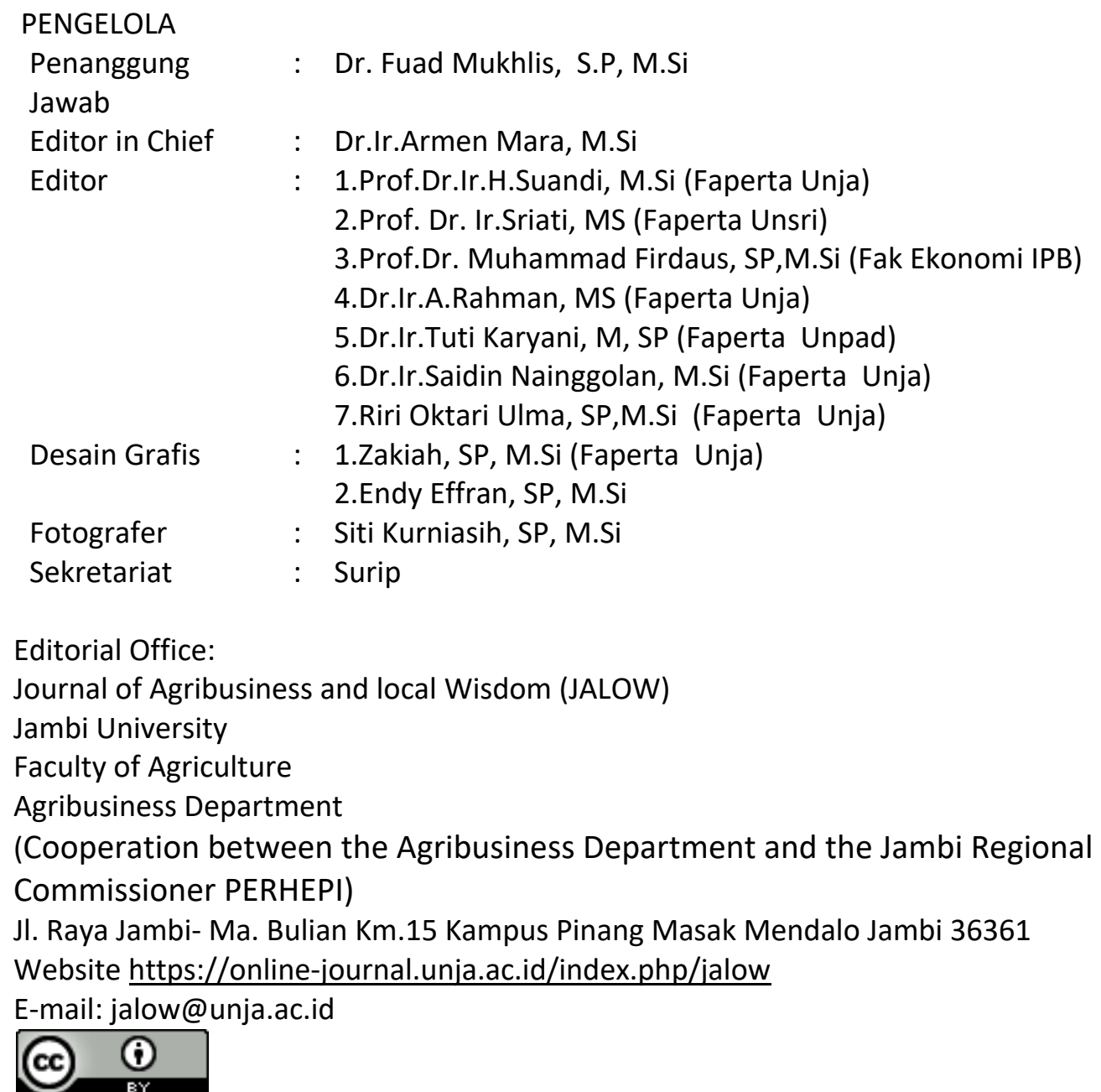

This work is licensed under a Creative Commons Attribution 4.0 International License. 


\section{Assalamualaikum wbwb}

\section{PENGANTAR}

Kondisi agribisnis tahun 2020 ini agak berbeda dengan tahun sebelumnya. Kebijakan penanggulangan Covid19 seperti "dirumah Aja, lockdown lokasi, Isolasi Mandiri, PSBB (Pembatasan Sosial Berskala Besar), dan Herd Immunity" telah merubah pola aktivitas masyarakat, khususnya di Kota-kota. Sebelumnya, berkejar2an dengan waktu untuk meningkatkan pendapatan dengan jalan menambah produktivitas dan menekan biaya telah dikagetkan oleh adanya ancaman pandemi Covid19 yang ada dimana-mana, semangat berkejar-kejaran tersebut kendur seketika.

Kegiatan perdagangan di Kota-kota besar maupun kota kecil telah mengalami kelesuan untuk semua lapisan, mulai dari pedagang kecil mikro, pedagang asongan atau gerobak, pedagang toko, mini market sampai perdagangan berskala besar, super market, dan mallmall. Hal ini menyebabkan terjadinya pengangguran, berkurangnya pendapatan masyarakat dan menurun drastisnya penerimaan pemerintah dari pajak. Selama masa isolasi, para konsumen melakukan belanja dengan sangat hati-hati. Pihak produsen merasakan berkurangnya permintaan. Oleh karena itu, walaupun kebijakan Covid19 tidak menghambat aktivitas produksi pertanian di lahan secara langsung namun karena permintaan berkurang maka berkurang pula pendapatan petani yang mengusahakan kebun atau sawah.

Kebiasaan konsumen yang selama ini lebih banyak makan di luar rumah berubah menjadi lebih banyak makan di rumah sendiri, masak sendiri atau pesan antar. Berbelanja yang semula mencari tempat2 yang banyak di kerumuni orang berubah ke tempat yang tidak ada kerumunannya, artinya rasa enak dan harga murah tidak lagi menjadi patokan utama bagi konsumen. Mereka lebih mengutamakan sehat dan terjamin dalam proses pembuatannya. Kesadaran adanya ancaman bahaya serangan Covid19 terhadap nyawa setiap orang telah menyebabkan berubah nya psikologi dan sosial masyarakat. Sebelumnya berpikir materialis dan untung rugi dari setiap kerja, sekarang mulai nampak adanya kepedulian terhadap perintah agama melaksanakan sholat dan bersedekah. Mulai terlihat adanya aktivitas sosial di tengah-tengah kota, ada kegiatan membagikan nasi bungkus kepada kaum duafah dan lapisan bawah, kegiatan membagikan sembako, membagikan ampelop berisi uang kertas, sampai pada aktivitas memberikan tip berupa uang dalam setiap kali berbelanja di pedagang-pedagang kecil.

Harapan untuk semua aktivitas-aktivitas positif tersebut berlangsung tidak sementara tapi menjadi karakter bagi setiap orang. Kalau aktivitas sosial ini terus dipertahankan oleh pelaku yang telah memulai nya tentu akan diikuti juga oleh yang lainnya. Diharapkan juga setiap pelaku agribisnis berskala kecil, baik yang disektor produksi pertanian maupun sektor industri pengolahan dan perdagangan dapat mengantisipasi perubahan prilaku konsumen tersebut dengan perubahan pola produksi yang sesuai sehingga peluang bisnis yang terlepas dari pola sebelumnya dapat ditangkap.

Demikian semoga JALOW untuk penerbitan ini bermanfaat untuk kita semua aamiin ya robbal aalamiin.

Waalaikumsalam wbwb

Editor in Chief

Dr.Ir.Armen Mara,M.Si 
DAFTAR ISI

\begin{tabular}{|c|c|c|}
\hline 1 & $\begin{array}{l}\text { ANALISIS RESPON PENAWARAN KOMODITI KEDELAI } \\
\text { DI KABUPATEN TANJAB TIMUR } \\
\text { Oleh Edison }\end{array}$ & $1-10$ \\
\hline 2 & 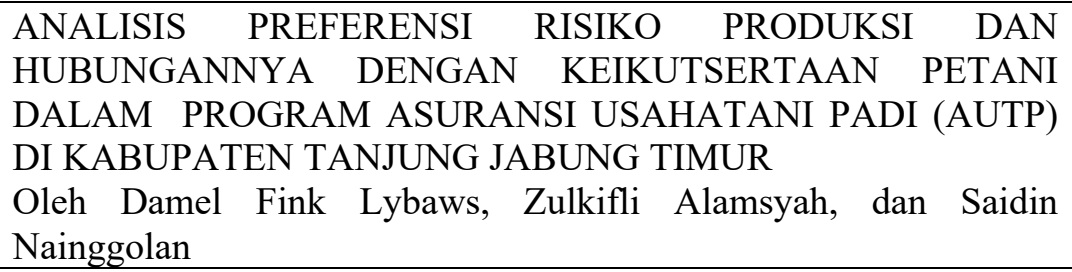 & $11-27$ \\
\hline 3 & $\begin{array}{l}\text { ANALISIS USAHA IKAN HIAS AIR TAWAR DI KOTA JAMBI (ANALYSIS } \\
\text { OF FRESH WATER ORNAMENTAL FISH IN JAMBI CITY) } \\
\text { Dody Hadisaputra, Ernawati, Suandi }\end{array}$ & $28-40$ \\
\hline 4 & $\begin{array}{l}\text { ANALISIS FAKTOR-FAKTOR YANG MEMPENGARUHI PRODUKSI } \\
\text { BOKAR (BAHAN OLAH KARET) DI KABUPATEN BATANGHARI } \\
\text { Oleh Elisabeth Lumban Gaol, Armen Mara, dan Riri Oktari UIma }\end{array}$ & $41-52$ \\
\hline 5 & $\begin{array}{l}\text { ANALISIS PENGAMBILAN KEPUTUSAN UNTUK PEMBELIAN } \\
\text { MAKANAN KEMASAN BERLOGO HALAL MUI (STUDI KASUS IBU } \\
\text { RUMAH TANGGA DI PERUMAHAN AUR DURI DAN PERUMNAS KOTA } \\
\text { BARU, KOTA JAMBI) } \\
\text { Oleh Putri Hana Jusia, Saad Murdy, Lavlinesia }\end{array}$ & $53-66$ \\
\hline 6 & \begin{tabular}{lrrrr} 
STRATEGI & ADAPTASI & PETANI & DALAM & \multicolumn{2}{l}{ MENGHADAPI } \\
RENDAHNYA & HARGA & JUAL & KELAPA & SAWIT DI \\
KECAMATAN & SUNGAI & BAHAR & KABUPATEN & MUARO \\
JAMBI & & & \\
Oleh Fiona Andini & ), Fuad Muchlis $^{2}$ ), Aulia Farida 2) \\
\end{tabular} & $67-73$ \\
\hline 7 & \begin{tabular}{lcllr}
\multicolumn{2}{l}{ KOLABORASI } & DALAM & PENGELOLAAN & \multicolumn{2}{c}{ PERKEBUNAN } \\
KELAPA SAWIT & RAKYAT & (STUDI KASUS: KUD & LUBUK \\
KARYA DAN & KUD & KAMPUNG & SURAU & KAB. \\
DHARMASRAYA & & & & \\
Oleh Yulistriani & & & & \\
\end{tabular} & $74-81$ \\
\hline 8 & $\begin{array}{l}\text { KEPUTUSAN PETANI SAWIT DALAM MENGKONVERSI } \\
\text { LAHAN KELAPA SAWIT MENJADI LAHAN PADI SAWAH DI } \\
\text { KECAMATAN BATANG ASAM KABUPATEN } \\
\text { TANJUNG JABUNG BARAT } \\
\text { Oleh Krielson Ompusunggu1), Arsyad Lubis2, Siti Kurniasih2 }\end{array}$ & $82-88$ \\
\hline 9 & $\begin{array}{l}\text { KAITAN BIAYA DAN TEKNIK PEREMAJAAN } \\
\text { KELAPA SAWIT RAKYAT } \\
\text { Oleh Nur Imdah Minsyah }\end{array}$ & $89-99$ \\
\hline 10 & $\begin{array}{l}\text { STRATEGI RANTAI PASOK KELAPA SAWIT DI PROVINSI } \\
\text { SUMATERA BARAT } \\
\text { Oleh Rahma Dzulqa1*), Rika Ampuh Hadiguna2) }\end{array}$ & 100 \\
\hline
\end{tabular}




\title{
STRATEGI RANTAI PASOK KELAPA SAWIT DI PROVINSI SUMATERA BARAT
}

\author{
Rahma Dzulqa ${ }^{1 *}$, Rika Ampuh Hadiguna ${ }^{2)}$ \\ ${ }^{1}$ Teknologi Industri Pertanian Fakultas Teknologi Pertanian Universitas Andalas \\ ${ }^{2}$ Teknik Industri Fakultas Teknik Universitas Andalas \\ ${ }^{*}$ Penulis untuk korespondensi: Tel.+6282382613214 \\ email: hadiguna@ft.unand.ac.id
}

\begin{abstract}
Indonesia is a major producer and exporter of CPO (Crude Palm Oil) in the world with a dominance of $56 \%$ of total CPO production in the world and $57 \%$ of the total exports of countries in the world. According to GAPKI data the volume of CPO oil exports and derivatives during 2018 reached 32.02 million tons. The Sumatra region has the largest oil palm center in Indonesia, West Sumatra is one of the developing provinces and has potential in oil palm plantations with a total production of 568680.4 tons / year (West Sumatra in Figures, 2019). However, there are sustainability issues that cover environmental, social and economic aspects which are strategic issues globally. This ongoing issue triggers various risks that can harm various parties and must be managed properly. One way to manage this problem is to supply chain efficiency. With the supply chain efficiency, success factors and palm oil supply chain strategies in the Province of West Sumatra can be determined. This research uses descriptive qualitative analysis method through interviews with related respondents and SWOT matrix. The results showed that success factors were found in the garden chain system, transportation from the garden to the factory, factory and transportation to the storage tank and consumers. The palm oil supply chain strategy obtained is the SO, WO, ST, WT strategy. To meet the integrated supply chain system and sustainable development of palm oil in addressing the existing issues, success factors and strategies for the palm oil supply chain in West Sumatra Province are needed in order to compete in the local and foreign markets.

Keywords: CPO, supply, chain
\end{abstract}

\section{PENDAHULUAN}

Produksi dan konsumsi dunia untuk minyak nabati sangat tinggi. Terutama komoditas minyak kelapa sawit merupakan minyak nabati yang paling banyak diproduksi dan dikonsumsi masyarakat dunia (Kustiana, 2016). Indonesia merupakan produsen sekaligus eksportir utama untuk CPO di dunia dengan dominasi $56 \%$ terhadap total produksi CPO (Crude Palm Oil) di dunia dan 57\% terhadap total ekspor negara -negara di dunia. Indonesia yang diikuti oleh Malaysia merupakan eksportir CPO terbesar di dunia. Luas areal perkebunan kelapa sawit Indonesia 12.298.450 Ha dengan total produksi 6.893.659 ton/tahun (Kelapa Sawit Dalam Angka, 2017). Menurut data GAPKI (Gabungan Pengusaha Kelapa Sawit Indonesia) volume ekspor minyak kelapa sawit mentah (CPO) dan turunannya sepanjang tahun 2018 mencapai 32,02 juta ton. Produksi minyak kelapa sawit Indonesia sebagian besar diekspor ke mancanegara dan sisanya dipasarkan di dalam negeri. Ekspor minyak kelapa sawit Indonesia menjangkau lima benua yaitu Asia, Afrika, Australia, Amerika, dan Eropa dengan pangsa utama di Asia.

Wilayah Sumatera memiliki sentra kelapa sawit terbesar di Indonesia, diantaranya adalah Riau, Sumatera Utara, Sumatera Selatan, Jambi dan Sumatera Barat. 
Sumatera Barat adalah salah satu provinsi yang sedang berkembang dan memiliki potensi pada perkebunan kelapa sawit. Dalam peningkatan produktivitas kelapa sawit harus memperhatikan isu keberlanjutan (sustainability) yang meliputi aspek lingkungan, aspek sosial, aspek ekonomi yang menjadi isu strategis secara global (Hadiguna, 2012). Beberapa tahun terakhir ini minyak sawit menjadi sorotan dunia karena banyaknya isu di pasar Internasional mengenai permasalahan lingkungan yang ditimbulkan oleh perkebunan kelapa sawit. Salah satunya, perkebunan kelapa sawit dianggap sebagai perkebunan dan industri yang tidak ramah lingkungan serta perkebunan yang berasal dari koversi lahan hutan.

Permasalahan dan isu berkelanjutan, mempengaruhi sistem rantai pasok kelapa sawit yang dimulai dari perkebunan, pengolahan kelapa sawit di pabrik hingga didistribusikan ke konsumen melalui kapal di pelabuhan menjadi terintegrasi secara baik sehingga dapat menurunkan efisiensi operasional (Hadiguna, 2010). Adanya isu berkelanjutan ini mendorong pentingnya dilakukan identifikasi faktor sukses untuk mengetahui variabel kegagalan dan kesuksesan rantai pasok kelapa sawit di Provinsi Sumatera Barat. Variabel kegagalan yang didapatkan jadi acuan untuk melaukan perbaikan-perbaikan terhadap sistem rantai pasok. Sementara variabel kesuksesan dijadikan acuan untuk menentukan strategi rantai pasok kelapa sawit.

Faktor sukses untuk rantai pasok kelapa sawit menjadi hal yang sangat penting untuk diidentifikasi jika dilihat dari kondisi yang terjadi dan isu keberlanjutan yang terjadi di Provinsi Sumatera Barat. Kondisi dan permasalahan yang terjadi harus segara diatasi untuk meningkatkan produktivitas dan menjamin pasokan-pasokan CPO ke negaranegara pengimpor minyak kelapa sawit (Hadiguna, 2013). Faktor sukses ini sebagai penentu keberhasilan rantai pasok industri sawit dalam memenuhi efisiensi operasional, sehingga dapat meningkatkan perekonomian, nilai tambah dan daya saing produk-produk kelapa sawit Provinsi Sumatera Barat di pasar dunia serta pembangunan kelapa sawit yang berkelanjutan dapat terwujud (Laporan Perekonomian Provinsi Sumatera Barat, 2018).

Penelitian ini memiliki dua tujuan. Pertama, tujuannya mengidentifikasi isu keberlanjutan kelapa sawit di Provinsi Sumatera Barat. Kedua, tujuannya merumuskan faktor sukses untuk rantai pasok kelapa sawit di Provinsi Sumatera Barat dan strategi rantai pasok kelapa sawit menggunakan matrik SWOT.

\section{METODE PENELITIAN}

Penelitian ini dilakukan di Provinsi Sumatera Barat. Lokasi penelitian dipilih secara purposive yaitu cara pengambilan sampel dengan secara sengaja. Wawancara dilaksanakan di industri pengolahan sawit dan di kantor GAPKI (Gabungan Pengusaha Kelapa Sawit) Sumatera Barat. Penelitian dilaksanakan pada bulan September sampai dengan bulan Oktober 2019.

Penelitian yang dilakukan merupakan studi kasus yaitu melakukan pengamatan dan pengambilan data melalui beberapa teknik pengumpulan data dan beberapa teknik analisis data. Sumber data primer diperoleh dari wawancara langsung dilapangan pada beberapa responden (Gabungan Pengusaha Kelapa Sawit Indonesia (GAPKI), petani 
kelapa sawit dan industri pengolahan kelapa sawit) dan data sekunder diperoleh dari laporan, catatan, dokumen, dan studi pustaka yang diperoleh dari hasil penelitian sebelumnya atau buku serta literatur yang relavan dengan penelitian yang dapat dipertanggung jawabkan, baik yang terdapat dalam usaha maupun luar usaha seperti Departemen Pertanian, Direktorat Jendral Perkebunan, Badan Pusat Statistik dan Dinas Perindustrian dan Perdagangan.. Penilitian ini bersifat analisis deskriptif kualitatif yang mana hanya menggambarkan dan menjelaskan bagaimana isu keberlanjutan terhadap rantai pasok kelapa sawit di Sumatera Barat.

Teknik analisis data yang dilakukan pada penelitian adalah analisis deskriptif kualitatif variabel isu keberlanjutan yang meliputi aspek lingkungan, aspek sosial, aspek ekonomi dan kondisi internal berupa kekuatan (strengths) dan kelemahan (weaknesses) serta kondisi eksternal dan ancaman (threats) rantai pasok kelapa sawit di Sumatera Barat. Untuk strategi rantai pasok analisis data menggunakan matrik SWOT.

\begin{tabular}{|c|c|c|}
\hline Faktor eksternal & $\begin{array}{l}\text { STRENGHTS (S) } \\
\text { Daftar Kekuatan } \\
\text { Internal }\end{array}$ & $\begin{array}{l}\text { WEAKNESSES (W) } \\
\text { Daftar Kelemahan } \\
\text { Internal }\end{array}$ \\
\hline OPPORTUNITIES (S) & STRATEGI SO & STRATEGI WO \\
\hline $\begin{array}{l}\text { Daftar Peluang } \\
\text { Eksternal }\end{array}$ & $\begin{array}{c}\text { Strategi yang } \\
\text { menggunakan } \\
\text { kekuatan untuk } \\
\text { memanfaatkan } \\
\text { peluang } \\
\end{array}$ & $\begin{array}{c}\text { Strategi yang } \\
\text { meminimalkan } \\
\text { kelemahan untuk } \\
\text { memanfaatkan peluang }\end{array}$ \\
\hline $\begin{array}{l}\text { THREATS (S) } \\
\text { Daftar Ancaman } \\
\text { Eksternal }\end{array}$ & $\begin{array}{c}\text { STRATEGI ST } \\
\text { Strategi yang } \\
\text { menggunakan } \\
\text { kekuatan untuk } \\
\text { mengatasi ancaman }\end{array}$ & $\begin{array}{c}\text { STRATEGI WT } \\
\text { Strategi yang menimalkan } \\
\text { kelemahan dan } \\
\text { menghindari ancaman }\end{array}$ \\
\hline
\end{tabular}

Gambar 2. Matrik SWOT (Sumber: Rangkuti, 2013)

\section{HASIL DAN PEMBAHASAN}

\section{Gambaran Umum Lokasi Penelitian}

Provinsi Sumatera Barat memiliki luas lahan perkebunan kelapa sawit sebesar 220.193,1 Ha dan total produksi 568 680,4 ton/tahun (Sumatera Barat Dalam Angka, 
2019). Daerah yang menjadi sentra kelapa sawit di Provinsi Sumatera Barat dapat dilihat pada Tabel 1 berikut:

Tabel 1. Luas lahan perkebunan rakyat kelapa sawit dan produksi Palm Oil di Provinsi Sumatera Barat Tahun 2018

\begin{tabular}{lcc}
\hline \multicolumn{1}{c}{ Kabupaten } & Luas Lahan $(\mathrm{Ha})$ & Produksi (Ton) \\
\hline Kep Mentawai & - & - \\
Pesisir Selatan & 39.461 & $76.327,90$ \\
Solok & 22,5 & 73,15 \\
Sijunjung & 11.323 & $37.329,73$ \\
Tanah Datar & - & - \\
Padang Pariaman & 1.379 & $2.876,48$ \\
Agam & 19.891 & $54.430,36$ \\
Lima Puluh Kota & 2.947 & $7.202,70$ \\
Pasaman & 4.305 & 10.700 \\
Solok Selatan & 4609 & $10.739,84$ \\
Dhamasraya & $32.261,6$ & $77.741,40$ \\
Pasaman Barat & 102.200 & 290.564 \\
\hline
\end{tabular}

(Sumber: Sumatera Barat Dalam Angka, 2019)

Crude Palm Oil (CPO) merupakan salah satu hasil komoditi utama Provinsi Sumatera Barat. Komoditi yang paling banyak di ekspor tahun 2018 adalah CPO sebanyak US\$1,1 miliar atau 69,25\%. Dibandingkan tahun 2017 maka volume minyak kelapa sawit turun 7,90 \%, sementara secara nilai komiditi ini turun 19,91 \% (Laporan Perekonomian Provinsi Sumatera Barat, 2018). Provinsi Sumatera Barat memiliki 31 industri yang memproduksi CPO dan 3 industri yang memproduksi minyak kernel sawit. Berikut ini merupakan daftar industri pengolahan kelapa sawit Sumatera Barat.

Tabel 2. Daftar Industri Pengolahan Kelapa Sawit di Provinsi Sumatera Barat.

\begin{tabular}{ll}
\hline \multicolumn{1}{c}{ Nama Perusahaan Penghasil CPO } & \multicolumn{1}{c}{ Lokasi } \\
\hline PT. Agrowiratama & Pasaman Barat \\
PT. Agro Wira Ligatsa & Pasaman Barat \\
PT. AMP Plantation & Agam \\
PT. Selago Makmur Plantation & Dhamasraya \\
PT. Andalas Agro Industri & Pasaman Barat \\
PT. Bakrie Pasaman Plantation & Pasaman Barat \\
PT. Berkat Sawit Sejahtera & Pasaman Barat \\
PT. BinaPratama Sakato & Dhamasraya \\
PT. Bintara Tani & Pasaman Barat \\
PT. Dhamasraya Lestarindo & Dhamasraya \\
PT. Dhamasraya Sawit & Dhamasraya \\
PT. Gersindo & Pasaman Barat \\
PT. Incasi Raya Pangian & Dhamasraya \\
PT. Incasi Raya (Olein) & Padang \\
PT. Incasi Raya Sodetan POM & Pesisir Selatan \\
PT. Kemilau Permata Sawit & Sijunjung \\
PT. Rimbo Panjang & Pasaman Barat
\end{tabular}




\begin{tabular}{ll} 
PT. Kencana Sawit & Solok Selatan \\
PT. Mutiara Agam & Agam \\
PT. Pasaman Marama & Pasaman Barat \\
PT. Pelalu Raya & Agam \\
PTPN VI OPHIR & Pasaman Barat \\
PTPN VI SOLSEL & SOLSEL \\
PT.Sari Buah Sawit & Pasaman Barat \\
PT. Sawita Pasaman & Pasaman Barat \\
PT. Sumatera Jaya & Pesisir Selatan \\
PT. Sumbar Andalas Kencana & Dhamasraya \\
PT. Tidar Kerinci Agung & Dhamasraya \\
PT. Usaha Inti Padang & Padang Pariaman \\
PT. Inkud Agritama & Pasaman Barat \\
PT. BinaPratama & Solok Selatan \\
\hline
\end{tabular}

(Sumber: Direktori Manufaktur Provinsi Sumatera Barat Tahun 2018)

\section{Sistem Rantai Pasok Kelapa Sawit}

Rantai pasok mengacu pada jaringan terpadu antara berbagai produsen yang memiliki tahapan transmisi yang berbeda sampai produk mendekati pengguna akhir (Hofbauer, 2011). Jaringan rantai pasok terdiri dari berbagai elemen seperti pemasok, produsen, pengumpul, pusat distribusi, industri dan pelanggan yang berarti pengadaan barang menggunakan bahan baku menghasilkan output dan kemudian disalurkan ke pasar dengan pengiriman tepat waktu (Drezner, 2004).

Sistem rantai pasok di Provinsi Sumatera Barat dimulai dari pemaneman Tandan Buah Segar (TBS). Aktivitas panen yang dilakukan adalah pengambilan TBS dari pohon kelapa sawit, kemudian TBS diangkut dan dikumpulkan. Ada yang menggunakan angkong dan sepeda motor. Setelah TBS dikumpulkan kemudian ditransportasikan ke pabrik dengan menggunakan truk. Setelah sampai di pabrik, TBS diterima di stasiun penerimaan untuk dilakukan penimbangan dan dilanjutkan dengan proses produksi hingga menghasilkan CPO. CPO ditransportasikan ke konsumen melalui darat (jalan Lintas Sumatera) dan jalur laut (Pelabuhan Teluk Bayur). Konsumen CPO ini berasal dari dalam (industri minyak goreng dan kosmetik) maupun luar negeri. Berikut ini merupakan gambar rantai pasok kelapa sawit di Sumatera Barat:

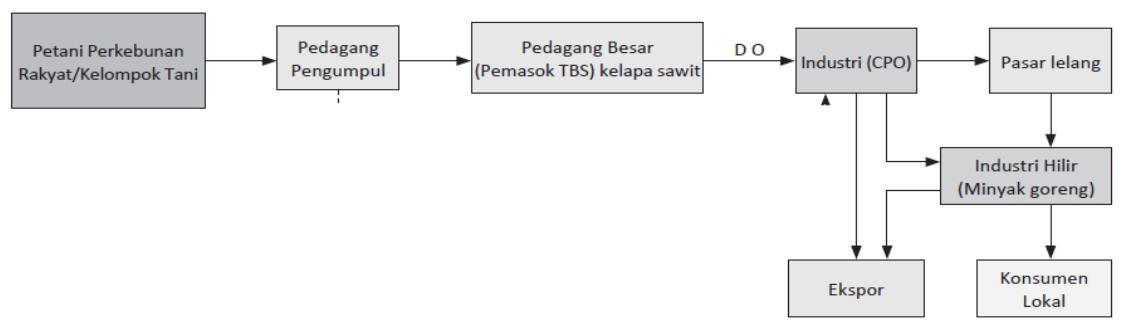

Gambar 3. Sistem rantai pasok kelapa sawit Provinsi Sumatera Barat 


\section{Isu Keberlanjutan}

Peningkatan produktivitas TBS (Tandan Buah Segar) tidak selalu berdampak positif karena terjadinya ketidakseimbangan suplai TBS dengan ketersediaan pabrik pengolah di Provinsi Sumatera Barat yang menyebabkan terjadinya distorsi harga pada tingkat petani kelapa sawit. Bahkan harga terpahit yang pernah dialami petani sebesar Rp. 300/kg. Petani tetap menjual hasil panen kelapa sawitnya daripada dibiarkan habis dimakan hama. Untuk harga saat ini bertahan pada Rp. 700/kg - Rp.1.000/kg. Adanya perbedaan harga tergantung dari akses terdekat ke pabrik. Seperti di Kabupaten Dhamasraya, sudah ada pengumpul dibawa ke pabrik yang ada di Jambi. Isu distorsi harga mempengaruhi aliran informasi rantai pasok dalam perencanaan pengolahan kelapa sawit menjadi CPO tidak terintegrasi di pabrik. Pertumbuhan produksi TBS dan produktivitas CPO yang semakin meningkat, namun pabrik pengolahan tidak bertambah. Solusi pada aspek ekonomi ini adalah perlunya penambahan pabrik pengolahan, sehingga dengan adanya pabrik yang siap menampung hasil panen dan meningkatkan harga jual.

Isu keberlanjutan pada aspek lingkungan adalah stigma masyarakat yang menganggap bahwa pengelolaan industri perkebunan kelapa sawit Indonesia mengabaikan kepentingan lingkungan. Yang paling popular adalah kegiatan pengembangan areal perkebunan sehingga menyebabkan bencana asap tahunan yang sangat merugikan masyarakat khususnya bagian Sumatera dan Kalimantan begitu juga dengan limbah hasil pengolahan kelapa sawit yang mencemari lingkungan. Isu ini terjadi pada PT. AWL Pasaman Barat, Setelah diuji Dinas Lingkungan Hidup setempat limbah yang dihasilkan telah melewati batas baku mutu yang ada. Limbah cair hasil pengolahan juga dibuang ke perkebunan warga setempat. Terhadap temuan itu Dinas Lingkungan Hidup langsung memasang plang pengumuman bahwa limbah dan pabrik tersebut dalam pengawasan.

Isu keberlanjutan dari aspek sosial adalah persengkataan lahan. Persengketaan lahan ini sering terjadi antara para petani maupun pemilik pabrik. Seperti yang terjadi pada 11 Agustus 2017 menurut harian metro andalas, ratusan warga Koja Pasaman Barat melakukan aksi demo terhadap PT. LIN yang menuntut atas lahan perkebunan sawit masyarakat sebesar 68 Ha selama ini tidak digubris oleh PT. LIN. Bahkan kabar yang ada PT. LIN mendapatkan sertifikat HGU secara tiba-tiba dan tanpa persetujuan masyarakat Koja. Persengketaan lain terjadi dengan PT. Wilmar International, ana perusahaan Wilmar PT. PMJ telah mengambil alih tanah komunitas tetangga Nagari Kinali Pasaman Barat dengan janji-janji untuk membangun area perkebunan kelapa sawit bagi masyarakat, namun janji tersebut tidak terlaksanakan. Secara total, sekitar 24 komunitas di Sumatera Barat kehilangan kendali atas tanah adat mereka karena diambil anak perusahaan Wilmar. Hal ini tertulis pada siaran pers oleh Zulkifli $\mathrm{S}, \mathrm{H}$ yayasan nagari institute 03 Desember 2018.

\section{Faktor-Faktor Sukses Rantai Pasok Kelapa Sawit}

Berdasarkan pemaparan rantai pasok kelapa sawit di Provinsi Sumatera Barat terdapat beberapa wilayah dimana faktor sukses dapat dikembangkan. Rantai kebun menjadi salah satu faktor sukses rantai pasok karena dari sini sistem rantai pasok dimulai. 
Adanya perizinan, sertifikat tanah yang jelas dan bebas dari lahan sengketa merupakan faktor sukses pada rantai kebun. Begitu juga dengan kepastian bahwa lahan telah telah sesuai dengan rancangan umum tata ruang wilayah/provinsi. Pembukaan lahan yang harus berpedoman kelestarian lingkungan, meminimalisir terjadinya erosi dan kerusakan tanah berdasarkan hasil AMDAL. Pengelolaan kebun sesuai dengan Standart Operatting Procedure (SOP) agar tidak menimbulkan kerugian dan penurunan kualitas kelapa sawit merupakan faktor sukses di rantai kebun.

Transportasi dari kebun ke pabrik merupakan salah satu rangkaian rantai pasok. Faktor sukses yang dapat ditemukan adalah alat transportasi yang memadai dan layak pakai sehingga tidak terjadi kesalahan pengiriman yang mengakibatkan keterlambatan. Muatan kelapa sawit terhadap kapasitas truk juga harus diperhatikan agar tidak menganggu transportasi ke pabrik. Jarak dari kebun ke pabrik diusahakan agar mengambil jalan yang tidak jauh, hal ini menimbulkan tingginya biaya transportasi dan menyebabkan harga yang diterima petani untuk TBS rendah. Kondisi jalur lalu lintas yang rusak juga menjadi faktor yang akan mengakibatkan keterlambatan pengiriman dan penurunan kualitas TBS karena truk pengangkut yang terjebak di jalan yang rusak.

Adanya kepastian bahwa TBS yang diterima telah sesua dengan standar yang berlaku merupakan faktor sukses yang ada di pabrik pengolahan. Perencanaan produksi dan kapasitas produksi harus direncanakan dan diinformasikan dengan tepat. Hal ini akan berpengaruh pada seluruh kegiatan produksi. Jika perencanaan tidak tepat maka akan mengakibatkan kelebihan TBS yang menumpuk di loading ramp dan kapasitas tangki timbun yang tidak dapat menampung CPO karena adanya kelebihan produksi. Peralatan dan mesin-mesin produksi harus terawat dengan baik karena jika tidak maka proses produksi terhenti sehingga terjadinya keterlambatan pengiriman CPO dan tida dapat memenuhi kebutuhan konsumen tepat waktu. Limbah pabrik juga merupakan faktor sukses yang ada di pabrik, karena jika tidak diolah dan menyebabkan pencemaran sehingga masyarakat sewaktu-waktu akan menuntut akan dampak lingkungan yang diterimanya.

Transportasi dari pabrik ke tangki timbun dan konsumen adalah rangkaian terakhir dari sistem rantai pasok kelapa sawit. Pertimbangan waktu pengiriman dan mempertimbangkan kondisi jalur lalu lintas yang rusak adalah salah satu faktor sukses tahap ini. Jalur lintas dari kota padang menuju pelabuhan Teluk Bayur mengalami kerusakan, hal ini akan sangat mempengaruhi sistem rantai pasok. Manajemen persediaan tangki timbun di pelabuhan juga harus diperhatikan agar saat kapal datang CPO dapat langsung dikirim ke konsumen.

\section{Strategi Rantai Pasok}

Adanya isu keberlanjutan dan faktor-faktor sukses dalam sistem rantai pasok kelapa sawit, maka dapat dirumuskan sebuah strategi agar sistem rantai pasok efektif dan efisien. Strategi tersebut dapat dirumuskan dengan mengetahui faktor internal dan eksternal dalam sistem rantai pasok. Setelah itu didapatkan kekuatan (strengths), kelemahan (weaknesses), peluang (opportunities) dan ancaman (threats) yang akan disusun dalam matrik SWOT. 


\begin{tabular}{|c|c|c|}
\hline Faktor Internal & $\begin{array}{l}\text { STRENGHTS (S) } \\
\text { 1. Lahan kelapa sawit luas } \\
\text { 2. Produktivitas meningkat }\end{array}$ & $\begin{array}{l}\text { WEAKNESSES (W) } \\
\text { 1. Kurangnya pabrik } \\
\text { pengolahan } \\
\text { 2. Pengembangan produk } \\
\text { kurang } \\
\text { 3. Saluran distribusi produk }\end{array}$ \\
\hline $\begin{array}{l}\text { OPPORTUNITIES (S) } \\
\text { 1. Potensi industri CPO di } \\
\text { Indonesia masih besar } \\
\text { 2. Permintaan pasar CPO } \\
\text { dunia meningkat } \\
\text { 3. Kebutuhan industri hilir } \\
\text { lokal meningkat } \\
\text { 4. Pertumbuhan produksi }\end{array}$ & $\begin{array}{c}\text { STRATEGI SO } \\
\text { 1. Optimalisasi lahan } \\
\text { perkebunan untuk } \\
\text { meningkatkan mutu dan } \\
\text { produktivitas kelapa sawit } \\
\text { 2. Membantu pengembangan } \\
\text { industry hilir dengan } \\
\text { melakukan pelatihan dan } \\
\text { Pendidikan masyarakat di } \\
\text { sekitar lingkungan pabrik }\end{array}$ & $\begin{array}{c}\text { STRATEGI WO } \\
\text { 1.Mengajukan saran kepada } \\
\text { pemerintah dan investor } \\
\text { untuk menambah pabrik } \\
\text { pengolahan supaya } \\
\text { produktivitas lebih tinggi } \\
\text { 2.Melakukan penetrasi pasar } \\
\text { 3.Memanfaatkan } \\
\text { pertumbuhan produksi yang } \\
\text { semakin meningkat } \\
\text { sehingga sarana dan } \\
\text { prasaranaakan dapat } \\
\text { ditingkatkan juga } \\
\text { 4.Membangun pusat-pusat } \\
\text { distribusi dan informasi CPO }\end{array}$ \\
\hline THREATS (S) & STRATEGI ST & STRATEGI WT \\
\hline $\begin{array}{l}\text { 1. Fluktuasi kondisi } \\
\text { perekonomian global. } \\
\text { 2. Isu keberlanjutan } \\
\text { 3. Black campaign } \\
\text { mengenai CPO } \\
\text { Indonesia. } \\
\text { 4. Perusahan pesaing } \\
\text { 5. Adanya produk } \\
\text { subtitusi }\end{array}$ & $\begin{array}{l}\text { 1.Peningkatan pengawasan } \\
\text { lahan perkebunan akan } \\
\text { ancaman dan isu-isu yang } \\
\text { akan menganggu } \\
\text { produktivitas. } \\
\text { 2.Penguatan dan } \\
\text { pengembangan kerjasama } \\
\text { jangka panjang dengan } \\
\text { perushaan produsen/mitra } \\
\text { untuk menjamin kontuinitas } \\
\text { ketersediaan produk }\end{array}$ & $\begin{array}{l}\text { 1. Bekerjasama dengan } \\
\text { pemerintah untuk } \\
\text { melakukan strategi } \\
\text { bersaing } \\
\text { 2. Meningkatkan jumlah } \\
\text { pabrik pengolahan di } \\
\text { Provinsi Sumatera Barat } \\
\text { 3. Peningkatan kerjasama } \\
\text { dengan negara-negara } \\
\text { pengimpor minyak sawit. } \\
\text { 4. Meningkatkan kerjasama } \\
\text { dengan perusahaan } \\
\text { mitra/produsen dalam } \\
\text { pengembangan dan } \\
\text { informasi produk }\end{array}$ \\
\hline
\end{tabular}

Gambar 4. Matrik SWOT (Sumber: Rangkuti, 2013) 


\section{KESIMPULAN DAN SARAN}

Faktor sukses terdapat pada sistem rantai kebun, transportasi dari kebun ke pabrik, pabrik dan transportasi ke tangki timbun dan konsumen. Strategi rantai pasok kelapa sawit di Provinsi Sumatera Barat adalah strategi optimalisasi lahan perkebunan untuk meningkatkan produktifitas dan menambah jumlah pabrik pengolahan kelapa sawit.

Strategi rantai pasok kelapa sawit di Provinsi Sumatera Barat ini agar dapat dijadikan sebagai bahan pertimbangan dalam pengambilan keputusan dalam hal pengembangan perkebunan dan industri kelapa sawit berkelanjutan.

\section{DAFTAR PUSTAKA}

Badan Pusat Statistik Provinsi Sumatera Barat, 2018. Direktori industri manufaktur besar dan sedang Provinsi Sumatera Barat. Catalog 1305027. 13 pp: 24-27.

Badan Pusat Statistik Provinsi Sumatera Barat, 2018. Laporan perekonomian Provinsi Sumatera Barat. Catalog 9199007.13 pp: 44-45.

Badan Pusat Statistik Provinsi Sumatera Barat, 2019. Provinsi Sumatera Barat dalam angka. Catalog 1102001.13 pp: 481-482.

Direktorat Jenderal Perkebunan. 2018. Kelapa sawit dalam angka 2016-2017. Kementrian Pertanian Indonesia. Pp: 66.

Drezner Z, Hamacher H.W, 2004. Facility Location: Applications and Theory. Springer Verlag Berlin and Heidelberg GmbH \& Co. K; International Strategic Management Journal. pp: 86-70.

Hadiguna, R. A, 2010. Perancangan Sistem Penunjang Keputusan Rantai Pasok dan Penilaian Risiko Mutu Pada Agroindustri Minyak Sawit Kasar. Disertasi. Institut Pertanian Bogor, Bogor.

Hadiguna, R. A, 2012. Model Penilaian Resiko Berbasis Kinerja untuk Rantai Pasok Kelapa Sawit Berkelanjutan di Indonesia. Jurnal Teknik Industri.14(1): 13-24.

Hadiguna, R. A. 2013. Faktor sukses rantai pasok kelapa sawit di Provinsi Jambi. Prosiding Seminar Inovasi Teknologi dan Rekayasa Industri 2013.

Hofbauer P, Wenninger C, 2011. Elastic collaboration for automotive supplier networks. Concurrent Enterprising (ICE), 17th International Conference on 2011; pp. 1-7.

Kustiana, D. (2016). Tinjauan pasar kelapa sawit. Laporan Penelitian Aset PT XYZ. www.academia.edu/14838249/Tinjauan_Pasar_Sawit. [Diakses 06 Oktober 2019].

Rangkuti, F. 2013. Teknik Membedah Kasus Bisnis Analisis SWOT. Penerbit PT. Gramedia Pustaka Utama: Jakarta. P. 55-56.

Ricco, M. (10 Agustus 2017). Warga Koja Kinali ancam akan pasang pintu portal di pintu masuk PT. LIN. https://www.metroandalas.co.id. [Diakses 11 Oktober 2019]. 